\title{
High Temperature Cyclic Oxidation Behavior of Ni and Co Based Superalloys
}

\author{
Deepa Mudgal*, Surendra Singh, Satya Prakash \\ Department of Metallurgical \& Materials Engineering, Indian Institute of Technology, \\ Roorkee 247667, India \\ *Corresponding Author:deep1dmt@iitr.ernet.in
}

\begin{abstract}
High temperature oxidation causes degradation of materials in aircraft, marine, industrial and land base gas turbines. To obviate this problem, oxidation behavior of Ni and Co based superalloys viz superni 600 and superco 605 (Midhani grade) has been studied in air at $900^{\circ} \mathrm{C}$. Both superalloys go through cyclic oxidation which consists of $1 \mathrm{hr}$ heating in silicon carbide tube furnace followed by 20 min cooling in ambient air. Weight change was taken by a digital electronic weighing balance having accuracy of $1 \mathrm{mg}$ after each cycle. Exposed alloys were characterized by XRD, FESEM and EDS. Result shows that the Co base superalloy superco 605 shows less weight gain as compare to superni 600. The oxide layer mainly contains oxides of $\mathrm{Cr}_{2} \mathrm{O}_{3}, \mathrm{NiO}$ and spinel $\mathrm{NiCr}_{2} \mathrm{O}_{4}$.
\end{abstract}

Keywords. Cyclic oxidation, SEM, EDAX

\section{INTRODUCTION}

Superalloys find wide application in aeronautics, space, nuclear, chemical, and petrochemical, power generation and furnace industries, where extreme temperatures, mechanical stresses and 
corrosive environments are encountered. They have been developed to achieve oxidation resistance by utilizing the concept of selective oxidation [1]. The development of oxidation resistance is based on addition of an elements namely chromium, aluminum, nickel and silicon which will oxidize selectively and produce protective oxide [2]. Although $\mathrm{Cr}_{2} \mathrm{O}_{3}$ is mainly responsible for oxidation resistance but it often have a negative effect on the mechanical properties in high temperature environment and are expensive. [3]. To overcome this problem, alloying elements are usually added to improve mechanical properties, including Mo, W, Ta, Re and $\mathrm{Nb}$ through the solid solution hardening and $\mathrm{Al}$ and Ta via formation of a $\gamma^{\prime}$ precipitate in a $\gamma$-nickel matrix. Carbon is used to improve grain boundary properties while $\mathrm{Al}$ and $\mathrm{Cr}$ are added to develop oxidation resistance. These alloys possess improved mechanical properties, such as stress rupture [4] and [5], [6] and fatigue resistance [7] and [8] .Superalloys also provide high creep strength, low thermal expansion, high thermal conductivity, good weld ability and resistance against high temperature oxidation corrosion $[9,10]$.

A number of investigations on the oxidation behavior $\mathrm{Ni}$ and $\mathrm{Co}$ based superalloys have already been reported. Ni based superalloys show good oxidation resistance due to the formation of protective oxide scales which is responsible for imparting resistance against high temperature oxidation [11, 12, and 13]. Liu [14] shows isothermal behavior of Co based superalloys that it can grow protective oxide scale at $900^{\circ} \mathrm{Cand} 1000^{\circ} \mathrm{C}$. He also observed that the scale was well adherent and found to consist mainly of $\mathrm{CoO}$ and some $\mathrm{Cr}_{2} \mathrm{O}_{3}$. It is concluded that superalloys are suitable for high temperature applications. Hence, the knowledge of reaction kinetics and the nature of surface scales formed during higher temperature oxidation are essential for evaluating the alloys for their use in high temperature application. The present study focuses on high temperature oxidation behavior of $\mathrm{Co}$ and $\mathrm{Ni}$ based superalloys in air at $900^{\circ} \mathrm{C}$ under cyclic condition.

\section{EXPERIMENTAL}

The Ni and Co based superalloys namely Superni 600 and superco 605 were procured from MIDHANI (India). The alloys were hot rolled and annealed with varying thickness of 5.5-8mm. The alloys are designated as A and B and their composition have been mentioned in Table 1 . 
Table 1. Composition of Superalloys.

\begin{tabular}{|c|c|c|c|c|c|c|c|c|}
\hline \multicolumn{10}{|c|}{ Elements, wt\% } \\
\hline Superalloys & Fe & Ni & Mn & Cr & W & Co & Si & C \\
\hline A & $10 . \max$ & Bal. & 0.5 & 15.5 & & & & \\
\hline B & 3.0 & 10.0 & 1.5 & 20.0 & 15.0 & Bal & 0.3 & 0.08 \\
\hline
\end{tabular}

The alloy sheets were cut into rectangular samples of size $15 \mathrm{mmx} 20 \mathrm{~mm}$. Thickness of both the samples have been reduced to $5 \mathrm{~mm}$. Specimens were mirror polished using emery papers of 220 , $320,600,800,1000$ and 1200 grit sizes followed by cloth polishing with alumina powder $(1 \mu)$. Samples were then washed with the distilled water and cleaned with acetone. The physical dimensions of samples were recorded carefully using digital vernier caliper of resolution $0.01 \mathrm{~mm}$ to evaluate their surface area. Weight measurement of samples as well as alumina boats has been done using digital weighting balance. The superalloys samples were exposed to cyclic oxidation in a silicon carbide tubular furnace. Each cycle consist of $1 \mathrm{hr}$ heating in the furnace at $900^{\circ} \mathrm{C}$ followed by 20 min cooling in the ambient air.

All the samples succeeding to cyclic oxidation test for 100 cycles at $900^{\circ} \mathrm{C}$. For this, each sample was kept in alumina boat and weight measurement of both the specimen and both has been taken before starting the experiment. This weight measurement has been taken after every cycle. The alumina boats used for the studies were also preheated for $8 \mathrm{hr}$ at $1200^{\circ} \mathrm{C}$ and were assumed that their weight will remain constant during the experiment.

\section{RESULTS AND DISCUSSION}

\subsection{Visual Observation}

The superalloys during oxidation show change in color due to oxide formation on the top of the surface at $900^{\circ} \mathrm{C}$. Oxide scale form due to the gas solid reaction between metal and oxygen present in environment. During initial cycles, silver lustrous scale form on the surface of Supeco 605. After forty five cycles some black spots appear on the surface. No change in color was 
observed after 50 cycles till the end of 100 cycles. Color of the oxide layer formed in first cycle oxide is green in color on the superalloy 600. Subsequently in second cycle the color changes to light grey and some greenish brown layer appear on the surface. During the end of the 100 cycles, color of the oxide turned into dark grey alongwith greenish scale on it.
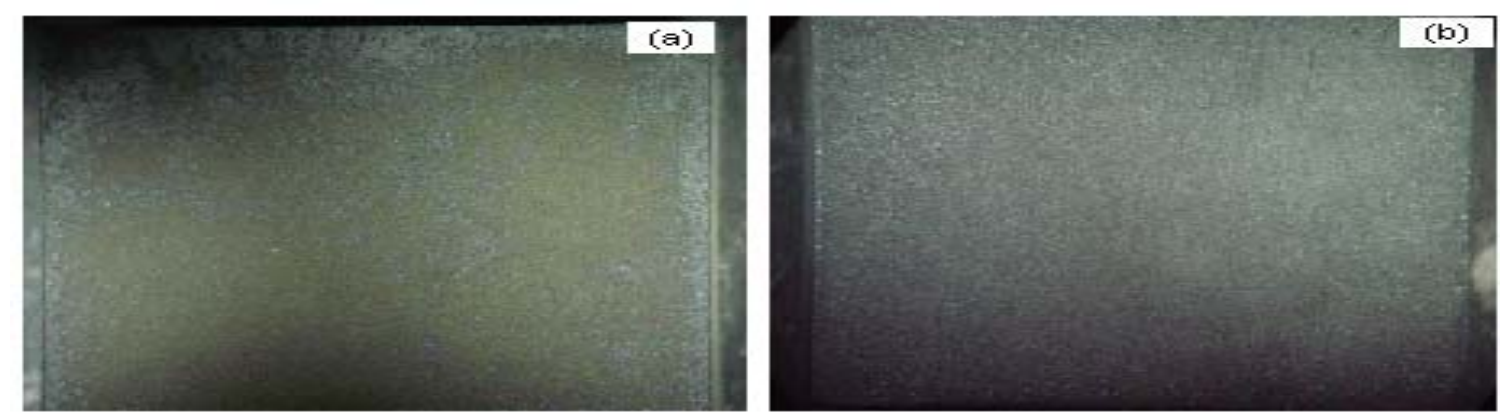

Fig 1 (a) Surface macrograph of superalloy superni 600 subjected to oxidation at $900 \mathrm{C}$ for 100 cycles

(b) Surface macrograph of superalloy superco 605 subjected to oxidation at $900 \mathrm{C}$ for 100 cycles

\subsection{Cyclic Oxidation.}

For oxidation, the mass gain corresponds to the mass of oxygen, which reacts with metal and gives the curve which is parabola in nature. Corrosion kinetic can be characterized by the factor $\mathrm{kp}$ defined as follows.

$$
\mathrm{k}_{\mathrm{p}}=\Delta \mathrm{M}^{2} / \mathrm{A}^{2} \mathrm{t}
$$

The comparison of $\mathrm{kp}$ value allows the quantification of the corrosion rate. Hence $\mathrm{kp}$ value for both the superalloys has been calculated which is given in table 2 . A small kp represents a low parabolic rate constant and thus protective behavior whereas a high $\mathrm{kp}$ corresponds to a higher reaction rate and non protective situation. As the kp value of superco 605 is less than superni 600 hence shows better oxidation resistance. The weight gain square $\left(\mathrm{mg}^{2} / \mathrm{cm}^{4}\right)$ vs time (number of cycles) and weight gain/ares $\left(\mathrm{mg} / \mathrm{cm}^{2}\right)$ vs number of cycles plots are shown in figure 2 to establish the rate law for oxidation. 
Table 2 Values of parabolic rate constant $\mathrm{k}_{\mathrm{p}}$

\begin{tabular}{ll}
\hline $\begin{array}{l}\text { Parabolic rate constant } \\
\left(\mathrm{k}_{\mathrm{p}}\right)\end{array}$ & $10^{-}$ \\
${ }^{10} \mathrm{~g}^{2} \mathrm{~cm}^{-4} \mathrm{~s}^{-1}$ & \\
\hline Superalloys Oxidation \\
\hline Superni 600 & 0.1211 \\
Superco 605 & 0.08 \\
\hline
\end{tabular}

(a)
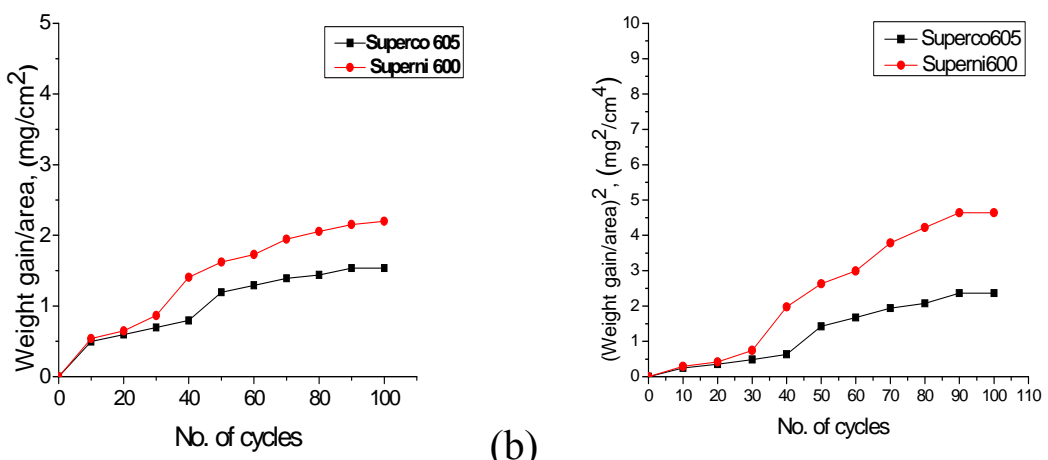

(b)

Figure. 2 (a) Weight gain/area vs number of cycles plot for superalloys subjected to cyclic oxidation (b) (Weight gain/area) ${ }^{2}$ vs number of cycles plot for superalloys subjected to cyclic oxidation.

\subsection{FESEM/EDAX Analysis of Scale}

Surface morphology of scale. FE SEM micrograph are showm in figure 3 (a) and (b) with EDS spectrum. From the result it has been clearly observed that $\mathrm{Cr}_{2} \mathrm{O}_{3}$ is the major oxide phase formed on both the superalloys which is responsible for the protection of the superalloy from the oxidation. In superni 600, major oxides phases other than $\mathrm{Cr}_{2} \mathrm{O}_{3}$ are $\mathrm{NiO}$ and $\mathrm{Fe}_{2} \mathrm{O}_{3}$. On the other hand predominant phases in superco 605 are $\mathrm{Cr}_{2} \mathrm{O}_{3}, \mathrm{NiO}, \mathrm{Fe}_{2} \mathrm{O}_{3}$ and $\mathrm{CoO}$. The protective oxide layer forms had almost uniform thickness all over the surface.

\subsection{Xray Diffraction Analysis of Scale}

$\mathrm{XRD}$ is a graph plotted between Intensity and diffraction angle $2 \theta$ to identify the phases present in the scale formed. This can be done by comparing the $d$ value of intensity peaks with the $d$ 
value given in the JCPDS files for the particular phase. X-ray diffractograms of the scale formed on the oxidized superalloys are shown in figure 4. The major phases indentified in superni 600 are $\mathrm{Cr} 2 \mathrm{O} 3, \mathrm{Fe}_{2} \mathrm{O}_{3}$ and $\mathrm{NiO}$ whereas in the scale of superco 605 an additional phase of $\mathrm{CoO}$ is noticed. Formation of spinel $\mathrm{NiCr}_{2} \mathrm{O}_{4}$ is also noticed in both the superalloys which provide oxidation resistance.

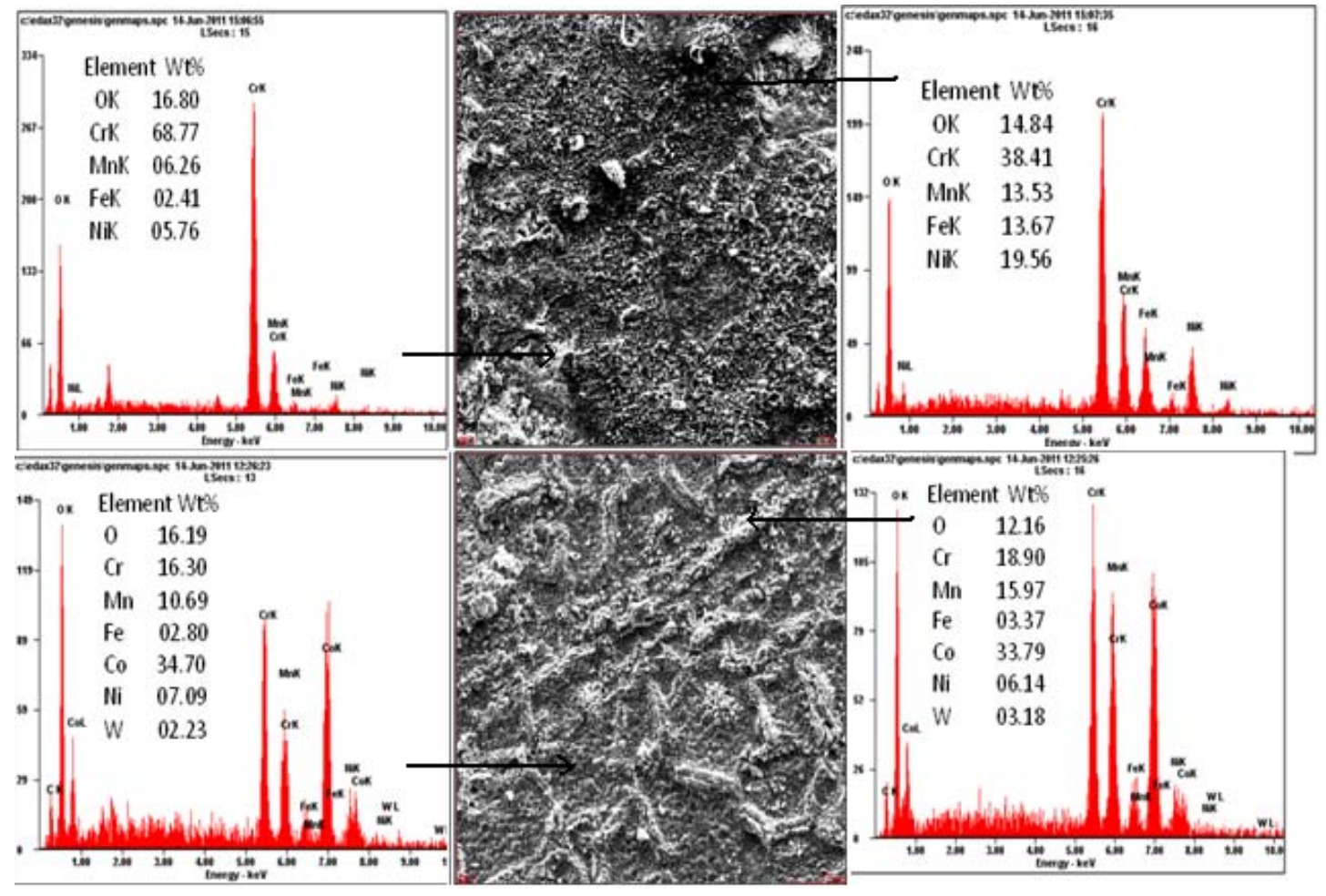

Figure. 3 (a) FE SEM surface morphology of oxide layers on Superni 600 after cyclic oxidation at $900^{\circ} \mathrm{C}$ (b) FE SEM surface morphology of oxide layers on Superco 605 after cyclic oxidation at $900^{\circ} \mathrm{C}$.

\section{DISCUSSION}

The weight change data for superalloys subjected to oxidation test in air environment respectively are plotted in figure2. It is clearly seen that weight gain is higher in initial cycles. Similar results have been discussed by Mahesh [12] and Harpreet [15]. Greenish layer appear due to presence of $\mathrm{NiO}$ in the scale of superni 600 . The oxide layer appeared to be compact and protective and had almost uniform thickness along the surface of specimen as observed by 
Mahesh [12] and Khalid [16]. Due to protective oxide layer, both the superalloys show good oxidation resistance.

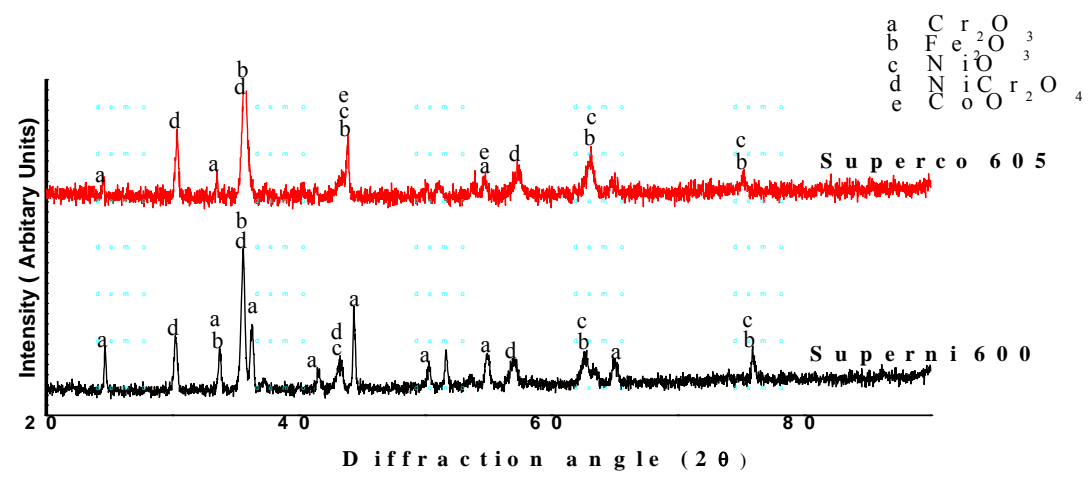

Figure. 4 XRD analysis of superni 600 and superco 605 after cyclic oxidation at $900^{\circ} \mathrm{C}$

\section{CONCLUSIONS}

1. The weight gain of superni 600 alloy is found to be more than weight gain of superco 605 .

2. Parabolic rate constant of superco 605 was low as compared to superni 600 . But both show good oxidation resistance in air under cyclic condition due to low $\mathrm{kp}$.

3. Protective oxides mainly consist of $\mathrm{Cr}_{2} \mathrm{O}_{3}, \mathrm{Fe}_{2} \mathrm{O}_{3}, \mathrm{NiO}$ and $\mathrm{NiCr}_{2} \mathrm{O}_{4}$ which was confirmed by $\mathrm{XRD}$ and EDAX analysis.

\section{REFERENCES}

[1] Pettit F S and Meier G H, (1985), Oxidation and hot corrosion of Superalloys, Superalloys 85, Eds. Gell M,Kartovich C S, Bricknel R H, Kent WB and Radovich J F, Met. Soc. Of AIME, Warrendale, Pensylvania, 651.

[2] G.H. Meier, Materials sciences and engineering. A120 (1989) p 1-11

[3] Chen, H.C., Liu, Z.Y. and Chuang, Y.C., (1993)," Degradation of plasma sprayed alumina and zirconia coatings on stainless steel during thermal cycling and hot corrosion," Thin solid films, Vol.223, No. 1, p 56-64. 
[4] D.W. MacLachlan and D.M. Knowles, (2001), "Modeling and prediction of the stress rupture behaviour of single crystal superalloys", Mater. Sci. Eng., Materials Science and Engineering, Volume 302, Issue 2, p 275-285

[5] Chao-Nan Weia, Hui-Yun Borb and Li Changa,(2011) "The influence of carbon addition on carbide characteristics and mechanical properties of CM-681LC superalloy using finegrain process", Journal of Alloys and Compounds, Volume 509, Issue 18, p 5708-5714.

[6] C.T. Liu, J. Ma and X.F. Sun, (2010), "Oxidation behavior of a single-crystal Ni-base superalloy between 900 and $1000{ }^{\circ} \mathrm{C}$ in air". Journal of Alloys and Compounds, Volume 491, Issues 1-2, p 522-526.

[7] J.H. Suwardie, R. Artiaga and J.L. Mier, (2002), "Thermal characterization of a Ni-based superalloy", Thermochimica Acta, Volumes 392-393, Pages 295-298.

[8] L. Felberbaum, K. Voisey, M. Gãumann, B. Viguier and A. Mortensen, (2001), Mater. Sci. Eng. A 299 p. 152.

[9] H. Guo, S. Gong, K.A. Khor and H. Xu, (2003) "Effect of thermal exposure on the microstructure and properties of EB-PVD gradient thermal barrier coatings", Surface and Coatings Technology Volume 168, Issue 1, p 23-29

[10] K. Shirvani, M. Saremi, A. Nishikata and T. Tsuru, (2003) "Electrochemical study on hot corrosion of Si-modified aluminide coated In-738LC in Na2SO4-20 wt.\% NaCl melt at $750{ }^{\circ}$ C”, Corros. Sci. Corrosion Science, Volume 45, Issue 5, p 1011-1021

[11] Subhash kamal, R. Jayaghanthan, and S. Prakash, (2010) "High temperature cyclic oxidation and hot corrosion behaviours of superalloys at 900C", Bull. Mater. Sci., Vol 33, No. 3, p 299-306.

[12] R.A. Mahesh, R. Jayaganthan and S. Prakash, (2008)“Oxidation behavior of selected Niand Fe- base Superalloys in air at $900 \mathrm{C}$ under cyclic condition”, Trans. Indian Inxst. Met., Vol61, No1, p 45-49

[13] C.T. Liua, J. Mab and X.F., (2009) "Oxidation behavior of a single-crystal Ni-base superalloy between 900 and $1000^{\circ} \mathrm{C}$ in air", Sunc.

[14] P.S. Liu and K.M. Liang, (2000) "High -Temperature oxidation behavior of the Co-base superalloys DZ40M in air Oxiadtion of Metals", Vol. 53, Nos3/4, 
[15] Harpreet Singh, Puri D and Prakash S,(2005) "Studies of plasma spray coatings on a Febase superalloy, their structure and high temperature oxidation behavior", Anti corrosion Methods and Materials, Vol. 52 Iss: 2, p 84 - 95.

[16] F.A. Khalid, N Hussain and K.A.Shah,(1997) "Microstructural characteristics of high temperature oxidation in Ni-based superalloy",Journal of Materials Engineering and Performance, Vol. 6, Nos. 2, p 219-222 